CONGENITAL HEART DISEASE

\title{
Left atrial and left ventricular function in healthy children and young adults assessed by three dimensional echocardiography
}

\author{
T Poutanen, E Jokinen, H Sairanen, T Tikanoja
}

Heart 2003;89:544-549

See end of article for authors' affiliations

Correspondence to

Dr Tuija Poutanen,

Lintuviidankatu 22, FIN

33340, Tampere, Finland;

tuija.poutanen@koti.tpo.fi

Accepted

10 January 2003

\begin{abstract}
Objective: To establish normal values of left atrial and left ventricular volumes and function in children and young adults using three dimensional echocardiography (3DE).

Methods: 169 healthy subjects aged 2 to 27 years were studied by digitised 3DE. 3DE was achieved using rotational acquisition of planes at $18^{\circ}$ intervals from the parasternal view for the left atrium and from the transthoracic apical view for the left ventricle with ECG gating and without respiratory gating. Left atrial and left ventricular volumes could be calculated throughout the heart cycle, and the respective time-volume curves were reconstructed in each subject.

Results: For the analysis the subjects were divided into five groups according to body surface area: $0.5-0.75 \mathrm{~m}^{2}, 0.75-1.0 \mathrm{~m}^{2}, 1.0-1.25 \mathrm{~m}^{2}, 1.25-1.5 \mathrm{~m}^{2}$, and over $1.5 \mathrm{~m}^{2}$. Mean (SD) left atrial maximum volume/body surface area was 19.6 (3.5), 21.7 (3.7), 22.0 (4.7), 24.5 (4.8), and 27.4 (6.4) $\mathrm{ml} / \mathrm{m}^{2}$; left ventricular maximum volume/body surface area was 50.1 (8.8), 54.9 (10.1), 56.4 (9.9), $58.7(11.0)$, and $64.4(10.3) \mathrm{ml} / \mathrm{m}^{2}$. Left atrial active emptying increased from $19 \%$ to $35 \%$ with age $(r=0.34, \mathrm{p}<0.001)$ and with decreasing heart rate $(r=-0.28, \mathrm{p}<0.001)$.

Conclusions: Transthoracic 3DE is well suited for studying the phasic changes in left atrial and left ventricular volumes in young children as well as in adults. The data obtained from 169 healthy subjects will serve as a reference for further studies in patients with various cardiac abnormalities.
\end{abstract}

A ccurate measurements of left atrial and left ventricular volumes and function are important in the management of patients with various cardiac abnormalities. M mode and cross sectional echocardiography are the most commonly used methods to measure left atrial and left ventricular volumes and function. However, the accuracy of the data obtained is limited by the geometric assumptions made about the shape of the left atrium and left ventricle and because of the slightly diverging positions and orientations of imaging planes. ${ }^{1}$ Cyclic changes in left atrial volumes are not directly obtainable by these methods as the shape of the left atrium changes during the heart cycle. Only a few data have been published on left atrial volume estimated by echocardiography in children. ${ }^{2}$

Radionuclide angiography and, more recently, magnetic resonance imaging (MRI) have been used to evaluate left ventricular systolic and diastolic function. ${ }^{45}$ With both methods a time-volume curve can be generated with moderate temporal resolution. The disadvantages of these methods are their expense, patient discomfort, the need for injection of radiopharmaceutical agents in nuclear scans, and the prolonged image acquisition time in MRI.

Three dimensional echocardiography (3DE) is a new non-invasive imaging technique that has been shown to be accurate in determining cardiac volume and mass. ${ }^{67} 3 \mathrm{DE}$ has been validated to measure left atrial and left ventricular volumes in children. ${ }^{8-13}$ Recently, we have shown the suitability of 3DE also for assessing phasic left atrial and left ventricular volumes in children. ${ }^{15}$ To our knowledge there are no published studies on the effect of age on left atrial and left ventricular volumes and function in healthy children or adults assessed by $3 \mathrm{DE}$.

In the present study we used digitised transthoracic 3DE to assess left atrial and left ventricular volumes throughout the heart cycle in 169 children and young adults.

\section{METHODS}

The study was carried out in Kuopio University Hospital, Finland. Written informed consent for the study was obtained from the parents or subjects. The study was approved by the research ethics committee of the hospital.

\section{Study population}

Altogether 169 healthy children and young adults, 85 male and 84 female, were enrolled in the study. Weight and height of all subjects were recorded and body surface area was calculated. ${ }^{16}$ No subject had heart disease, as judged by history, clinical examination, and echocardiography. For the analysis the subjects were divided into five groups according to body surface area: $0.5-0.75 \mathrm{~m}^{2}, 0.75-1.0 \mathrm{~m}^{2}, 1.0-1.25 \mathrm{~m}^{2}, 1.25-$ $1.5 \mathrm{~m}^{2}$, and over $1.5 \mathrm{~m}^{2}$. The clinical details of the subjects are shown in table 1 .

\section{Echocardiographic examination}

Transthoracic echocardiographic examination was undertaken with the patient lying supine or in the left lateral semirecumbent position. Sedation was not used. Examinations were carried out by a single observer (TP) using a GE Vingmed System Five ultrasound scanner (Horten, Norway) and saved in digital form on the hard disk of the ultrasound scanner. The transducer frequencies used were $2.2 \mathrm{MHz}$ octave, $3.5 \mathrm{MHz}$, and $5 \mathrm{MHz}$. Standard parasternal, apical, and subcostal views were used. 3DE was done using rotational image acquisition from the parasternal long axis view for left atrium and from

Abbreviations: EDV, end diastolic volume; ESV, end systolic volume $\mathrm{LAAE} \%$, percentage of left atrial active emptying; LAPE\%, percentage of left atrial passive emptying; MRI, magnetic resonance imaging; PER, peak ejection rate; PFR, peak filling rate; $3 D E$; three dimensional echocardiography 
Table 1 Clinical characteristics of the subjects

\begin{tabular}{llllll}
\hline \multicolumn{7}{l}{ Body surface area } & & & \\
\cline { 2 - 6 } & $0.5-0.75 \mathrm{~m}^{2}$ & $0.75-1.0 \mathrm{~m}^{2}$ & $1.0-1.25 \mathrm{~m}^{2}$ & $1.25-1.5 \mathrm{~m}^{2}$ & $>1.5 \mathrm{~m}^{2}$ \\
\hline $\mathrm{n}$ & 16 & 42 & 34 & 29 & 48 \\
Age (years) & $3.7(1.0)$ & $7.0(1.3)$ & $9.9(1.6)$ & $12.5(1.6)$ & $17.3(3.6)$ \\
Sex & $\mathrm{M} 8 \mathrm{~F} 8$ & $\mathrm{M} 22 \mathrm{~F} \mathrm{20}$ & $\mathrm{M} 17 \mathrm{~F} 17$ & $\mathrm{M} 15 \mathrm{~F} 14$ & $\mathrm{M} \mathrm{23} \mathrm{F} 25$ \\
$\mathrm{Height}(\mathrm{cm})$ & $99.3(7.3)$ & $121.1(6.5)$ & $139.5(5.2)$ & $152.9(5.9)$ & $168.9(9.6)$ \\
Weight $(\mathrm{kg})$ & $15.9(2.5)$ & $23.382 .7)$ & $32.8(3.2)$ & $44.2(4.3)$ & $64.3(11.1)$ \\
BSA $\left(\mathrm{m}^{2}\right)$ & $0.7(0.1)$ & $0.9(0.1)$ & $1.1(0.1)$ & $1.4(0.1)$ & $1.7(0.2)$ \\
SBP (mm Hg) & $104(7)$ & $105(10)$ & $103(6)$ & $108(8)$ & $119(10)$ \\
DBP $(\mathrm{mm} \mathrm{Hg})$ & $60(8)$ & $65(12)$ & $62(8)$ & $65(8)$ & $67(10)$ \\
Heart rate (beats/min) & $100(16)$ & $84(10)$ & $76(10)$ & $73(8)$ & $67(12)$ \\
\hline
\end{tabular}

Values are mean (SD).

BSA, body surface area; DBP, diastolic blood pressure; SBP, systolic blood pressure.

the apical view for left ventricle, with ECG gating and without respiratory gating. The three dimensional echocardiographic method used has been described in detail in our earlier reports, which showed closely similar left atrial and left ventricular volumes and left ventricular mass by $3 \mathrm{DE}$ and MRI. ${ }^{14} 15$

\section{Echocardiographic analysis}

The echocardiographic data were analysed by a single observer (TP). Previous studies showed good intraobserver and interobserver repeatability of the measurements. ${ }^{14}{ }^{15}$

The three dimensional datasets were analysed with a detached computer. Left atrial cyclic volume change was calculated as the difference between maximum and minimum left atrial volumes. The atrial stroke volume (active emptying) is the volume reduction from the onset of atrial systole to the minimum volume at the end of diastole. The last $15 \%$ of the heart cycle was chosen to represent this time period of diastole. The passive emptying of left atrial volume was defined as the left atrial maximum volume minus the left atrial volume at the onset of atrial systole. The passive emptying percentage $(\mathrm{PE} \%=\mathrm{PE} /[$ left atrial maximum volume - left atrial minimum volume $\left.]^{*} 100\right)$ and active emptying percentage $(\mathrm{AE} \%=\mathrm{AE} /[$ left atrial maximum volume - left atrial minimum volume]*100) were calculated.

Left ventricular ejection fraction was calculated from end diastolic volume (EDV) and end systolic volume (ESV). Peak ventricular ejection rate (PER) and peak filling rate (PFR)
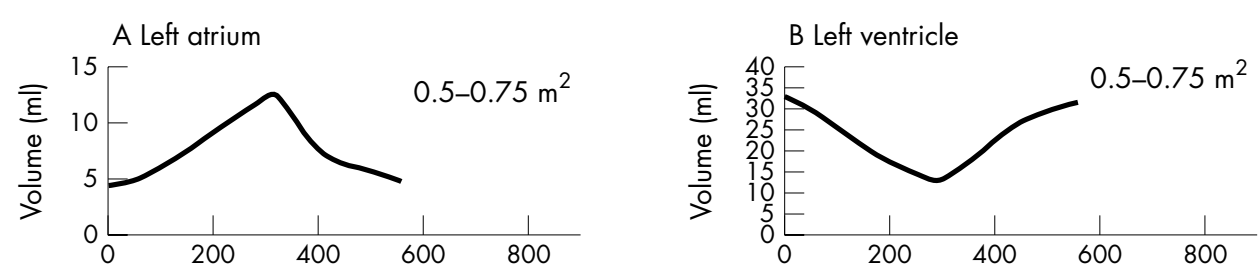

Figure 1 Averaged left atrial and left ventricular time-volume curves during the heart cycle in five body surface area groups.
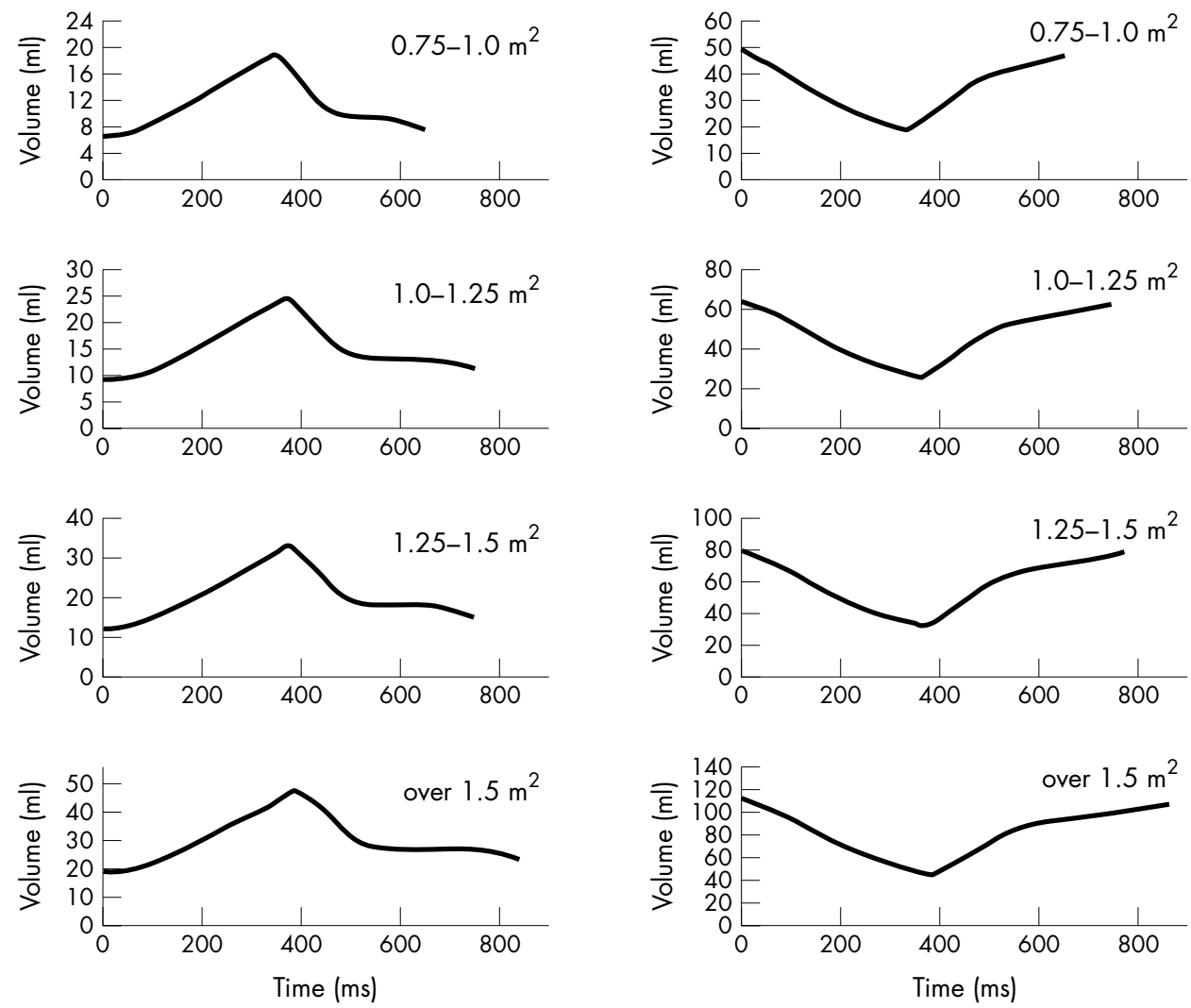
Table 2 Three dimensional echocardiography findings for the left atrium of the subjects

\begin{tabular}{llllll}
\hline \multicolumn{5}{l}{ Body surface area } \\
\cline { 2 - 6 } & $0.5-0.75 \mathrm{~m}^{2}$ & $0.75-1.0 \mathrm{~m}^{2}$ & $1.0-1.25 \mathrm{~m}^{2}$ & $1.25-1.5 \mathrm{~m}^{2}$ & $>1.5 \mathrm{~m}^{2}$ \\
\hline Subjects $(\mathrm{n})$ & 16 & 42 & 34 & 29 & 48 \\
LA maximum volume $(\mathrm{ml})$ & $12.8(2.8)$ & $19.1(3.4)$ & $25.0(5.8)$ & $33.6(6.8)$ & $47.8(13.5)$ \\
Maximum volume/BSA $\left(\mathrm{ml} / \mathrm{m}^{2}\right)$ & $19.6(3.5)$ & $21.7(3.7)$ & $22.0(4.7)$ & $24.5(4.8)$ & $27.4(6.4)$ \\
LA minimum volume $(\mathrm{ml})$ & $4.4(1.1)$ & $6.7(1.4)$ & $8.8(2.4)$ & $12.5(3.3)$ & $18.2(6.0)$ \\
Minimum volume/BSA $\left(\mathrm{ml} / \mathrm{m}^{2}\right)$ & $6.8(1.4)$ & $7.5(1.5)$ & $7.8(1.9)$ & $9.1(2.2)$ & $10.4(2.9)$ \\
LA mid-diastolic volume $(\mathrm{ml})$ & $6.2(1.6)$ & $9.8(2.0)$ & $13.2(3.3)$ & $18.6(4.3)$ & $27.4(9.0)$ \\
Mid-diastolic volume/BSA $\left(\mathrm{ml} / \mathrm{m}^{2}\right)$ & $9.5(2.1)$ & $11.1(2.0)$ & $11.6(2.7)$ & $13.5(2.9)$ & $15.6(4.3)$ \\
LA cyclic volume change $(\mathrm{ml})$ & $8.4(2.0)$ & $12.5(2.6)$ & $16.1(3.9)$ & $21.1(5.0)$ & $29.6(9.1)$ \\
Cyclic volume change/BSA $\left(\mathrm{ml} / \mathrm{m}^{2}\right)$ & $12.8(2.6)$ & $14.1(3.0)$ & $14.2(3.3)$ & $15.4(3.7)$ & $17.0(4.5)$ \\
LA stroke volume $(\mathrm{ml})$ & $1.8(0.8)$ & $3.2(1.1)$ & $4.3(1.4)$ & $6.1(1.7)$ & $9.2(4.0)$ \\
Stroke volume/BSA $\left(\mathrm{ml} / \mathrm{m}^{2}\right)$ & $2.8(1.2)$ & $3.6(1.2)$ & $3.8(1.2)$ & $4.4(1.2)$ & $5.2(2.1)$ \\
\hline Values are mean $(S D)$. & & & & & \\
BSA, body surface area; LA, left atrium. & & & & & \\
\hline
\end{tabular}

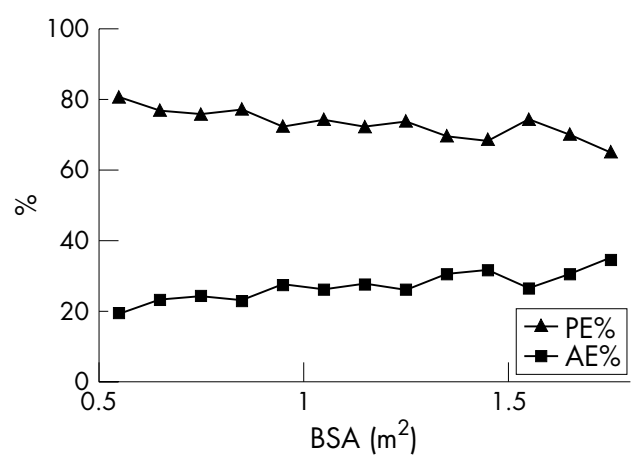

Figure 2 Age related changes in left atrial active emptying (AE\%) and passive emptying (PE\%) percentages. Left atrial $\mathrm{AE} \%$ and $\mathrm{PE} \%$ were calculated for $0.1 \mathrm{~m}^{2}$ body surface area groups (six to 21 subjects per group, mean age of group 2.8-17.9 years).

represent the greatest volume change per unit time during three frame intervals in 3DE recording (on average $40 \mathrm{~ms}$ ) in the ejection phase and in the filling phase of the time-volume curve. The rates of the left atrial and left ventricular volume changes were normalised by left atrial cyclic volume change and left ventricular stroke volume, respectively.

Mean time-volume curves of left atrium and left ventricle were calculated to obtain a visually informative representation of the volume changes in the subjects, as previously described..$^{14} 15$

\section{Statistical analysis}

Differences between means were assessed with Student's paired or unpaired $t$ test or one way analysis of variance. The Kolmogorov-Smirnov test with was used to check the normal distribution of variables. In case of non-normality the non-parametric Mann-Whitney/Wilcoxon test was used.
Pearson's correlation coefficient was used. The data are given as mean (SD).

\section{RESULTS}

All 3DE examinations were carried out successfully, and manual tracing of images was possible. The acquisition time for a 3DE dataset was 10-15 seconds, depending on the frame rate used and the heart rate. Image transfer to the detached computer took 2-3 minutes. Tracing of the left atrial and left ventricular volumes took 60-110 minutes per patient, depending on image quality and the number of frames.

The clinical details of the subjects are presented in table 1. All subjects were in good clinical condition with normal exercise tolerance. Seven children had asthma without symptoms at the time of examination. Three of the children with asthma were on treatment with inhaled corticosteroids.

\section{Echocardiography}

Figure 1 shows the time-volume curves of left atrium and left ventricle in each body surface area group. The different phases in left atrial and left ventricular volume changes and their dependency on heart rate are clearly seen in the curves.

\section{Left atrial volumes}

Data on left atrial volumes by $3 \mathrm{DE}$ are shown in table 2 . Left atrial maximum and minimum volumes correlated well with body surface area $(r=0.88$ and 0.85 , respectively; both $\mathrm{p}<0.001)$ and height $(r=0.84$ and 0.82 ; both $\mathrm{p}<0.001)$. Left atrial volume per unit body surface area increased with growth. Figure 2 shows the percentages of left atrial passive emptying (LAPE\%) and left atrial active emptying (LAAE\%) in relation to body surface area. The proportion of active emptying increased with body surface area and age $(r=0.39$ and $0.34 ; \mathrm{p}<0.001)$. The simultaneous decrease in heart rate showed a similar correlation for LAAE\% $(r=-0.28$;

Table 3 Three dimensional echocardiography findings for the left ventricle of the subjects

\begin{tabular}{|c|c|c|c|c|c|}
\hline & \multicolumn{5}{|c|}{ Body surface area } \\
\hline & $0.5-0.75 \mathrm{~m}^{2}$ & $0.75-1.0 \mathrm{~m}^{2}$ & $1.0-1.25 \mathrm{~m}^{2}$ & $1.25-1.5 \mathrm{~m}^{2}$ & $>1.5 \mathrm{~m}^{2}$ \\
\hline Subjects & 16 & 42 & 34 & 29 & 48 \\
\hline $\mathrm{EDV}(\mathrm{ml})$ & $32.9(7.5)$ & $48.7(10.3)$ & $64.2(13.1)$ & $80.8(16.1)$ & $112.1(24.8)$ \\
\hline EDV/BSA $\left(\mathrm{ml} / \mathrm{m}^{2}\right)$ & $50.1(8.8)$ & 54.9 (10.1) & $56.4(9.9)$ & 58.7 (1 1.0) & $64.4(10.3)$ \\
\hline $\mathrm{ESV}(\mathrm{ml})$ & $13.0(3.1)$ & $19.1(4.2)$ & $25.6(6.0)$ & $32.5(8.5)$ & $46.4(11.6)$ \\
\hline ESV/BSA $\left(\mathrm{ml} / \mathrm{m}^{2}\right)$ & $19.8(3.9)$ & $21.5(4.3)$ & $22.5(4.6)$ & $23.6(5.8)$ & $26.6(5.0)$ \\
\hline SV (ml) & $19.9(4.9)$ & $29.6(6.6)$ & $38.6(7.9)$ & $48.3(8.4)$ & $65.7(14.4)$ \\
\hline $\mathrm{SV} / \mathrm{BSA}\left(\mathrm{ml} / \mathrm{m}^{2}\right)$ & $30.4(5.8)$ & $33.4(6.4)$ & $34.0(6.1)$ & $35.1(5.9)$ & $38.0(6.2)$ \\
\hline $\mathrm{EF}(\%)$ & $60.5(3.8)$ & $60.8(3.2)$ & $60.2(3.4)$ & $60.1(3.2)$ & $58.8(3.4)$ \\
\hline
\end{tabular}

Values are mean (SD)

BSA, body surface area; EDV, end diastolic volume; EF, ejection fraction; ESV, end systolic volume; SV, stroke volume. 
Table 4 Peak filling rates and peak emptying rates calculated for left atrium and left ventricle from three dimensional echocardiographic time-volume data

\begin{tabular}{|c|c|c|c|c|c|}
\hline & \multicolumn{5}{|c|}{ Body surface area } \\
\hline & $0.5-0.75 \mathrm{~m}^{2}$ & $0.75-1.0 \mathrm{~m}^{2}$ & $1.0-1.25 \mathrm{~m}^{2}$ & $1.25-1.5 \mathrm{~m}^{2}$ & $>1.5 \mathrm{~m}^{2}$ \\
\hline Subjects (n) & 16 & 42 & 34 & 29 & 48 \\
\hline \multicolumn{6}{|l|}{ Left atrium } \\
\hline PFR $(\mathrm{ml} / \mathrm{s})$ & $42.0(14.5)$ & $51.3(9.8)$ & $63.2(16.1)$ & $83.3(18.6)$ & $112.8(34.7)$ \\
\hline PFR/cyclic volume change (I/s) & $5.0(1.0)$ & $4.2(0.5)$ & $3.9(0.5)$ & $4.0(0.5)$ & $3.9(0.6)$ \\
\hline $\operatorname{PER}(\mathrm{ml} / \mathrm{s})$ & $-80.8(18.5)$ & $-108.3(27.5)$ & $-124.1(35.1)$ & $-162.0(43.5)$ & $-202.9(57.1)$ \\
\hline $\begin{array}{l}\text { PER/cyclic volume change (I/s) }\end{array}$ & $-9.9(2.2)$ & $-8.7(1.4)$ & $-7.7(1.4)$ & $-7.7(1.4)$ & $-7.1(1.6)$ \\
\hline \multicolumn{6}{|l|}{ Left ventricle } \\
\hline $\operatorname{PER}(\mathrm{ml} / \mathrm{s})$ & $-98.9(25.7)$ & $-133.8(28.3)$ & $-154.7(38.2)$ & $-198.1(33.1)$ & $-265.5(64.2)$ \\
\hline PER/SV (I/s) & $-5.1(1.4)$ & $-4.6(0.7)$ & $-4.0(0.7)$ & $-4.1(0.6)$ & $-4.1(0.8)$ \\
\hline PFR (ml/s) & $124.3(23.1)$ & $169.0(39.8)$ & $225.3(64.0)$ & $264.8(49.4)$ & $320.3(76.6)$ \\
\hline PFR/SV (I/s) & $6.4(1.1)$ & $5.8(1.1)$ & $5.9(1.3)$ & $5.5(0.9)$ & $5.0(1.1)$ \\
\hline
\end{tabular}

Values are mean (SD).

PER, peak ejection rate; PFR, peak filling rate; SV, stroke volume.

$\mathrm{p}<0.001)$. In a linear regression model including both age and heart rate the effect of age for LAAE\% was significant $(p=0.004)$, while the effect of heart rate remained nonsignificant. No differences between boys and girls were found in left atrial maximum and minimum volumes.

\section{Left ventricular volumes}

The 3DE findings for the left ventricle are presented in table 3. Estimates for EDV and ESV correlated well with body surface area $(r=0.91$ and $r=0.89$, respectively; both $\mathrm{p}<0.001)$ and height $(r=0.89$ and $r=0.86 ; \mathrm{p}<0.001)$. Left ventricular volumes/body surface area increased with increasing age. EDV and ESV estimates tended to be greater in boys than in girls, but significance was achieved only in the body surface area group over $1.5 \mathrm{~m}^{2}$ ( $\mathrm{p}<0.001$ for both), and in the group $0.75-$ $1.0 \mathrm{~m}^{2}$ for EDV alone $(\mathrm{p}=0.047)$.

\section{Left atrial and left ventricular PER and PFR}

The results of systolic and diastolic indices calculated for left atrium and left ventricle are presented in table 4 . Left atrial PER, PFR, PER/cyclic volume change, and PFR/cyclic volume change correlated with heart rate $(r=0.50,-0.48,-0.43$, and 0.50 , respectively; all $\mathrm{p}<0.001)$. Left ventricular PER, PFR, $\mathrm{PER} /$ stroke volume, and PFR/stroke volume showed similar correlations with heart rate $(r=0.57,-0.55,-0.47$ and 0.46 , respectively; all $\mathrm{p}<0.001)$.

\section{DISCUSSION}

In this study left atrial and left ventricular volumes were measured by 3DE throughout the heart cycle and the respective time-volume curves were reconstructed in 169 healthy children and young adults. Changes related to increasing body surface area and age and simultaneously decreasing heart rate were seen both in left atrial and left ventricular volumes.

Left atrial and left ventricular volumes calculated per unit of body surface area increased with growth. Estimates of left atrial volume obtained in this study exceeded the normal values measured by cross sectional echocardiography in children. $^{2}$ The underestimation of left atrial volumes measured by cross sectional echocardiography compared with 3DE and MRI has been reported recently. ${ }^{7}$ Also, validation studies have shown a good correlation between 3DE and MRI measurements of left atrial volumes. ${ }^{71}{ }^{17}$ In an angiographic study of 21 normal children, estimates of left atrial volumes normalised to body surface area were smaller in infants than in older children. ${ }^{18}$ Our study confirms these findings. However, estimates of left atrial cyclic volumes by both cross sectional echocardiography and angiography are crude owing to the distinctly changing shape of the left atrium in different phases of the heart cycle. The suitability of 3DE for studies in outpatients favours its use over MRI, the other method capable of three dimensional presentation. We thus believe that our results serve as ample reference data for further use.

The effect of age on left atrial function has recently been studied by cross sectional acoustic quantification in a large group of normal subjects aged 3 to 79 years. ${ }^{19}$ Active left atrial emptying increased from $24 \%$ to $56 \%$ and passive left atrial emptying decreased from $76 \%$ to $44 \%$ between the first and eighth decades. In our study active emptying percentage (AEPE\%) of the left atrium increased with age, from 19\% (mean body surface area $0.6 \mathrm{~m}^{2}$, age 2.8 years) to $35 \%$ (mean body surface area $1.9 \mathrm{~m}^{2}$, age 17.9 years), which is consistent with earlier findings. ${ }^{19}{ }^{20}$ The increase in left atrial active emptying with age was associated with a decrease in heart rate and a simultaneous increase in left atrial volume/body surface area with growth. The increase in left atrial contractile function may in part reflect greater left atrial volumes at the onset of left atrial contraction (Starling effect). It has been reported earlier that left atrial size at the onset of atrial contraction is a major determinant of left atrial ejection force. ${ }^{21} \mathrm{~A}$ decreasing heart rate might in part explain the increase in left atrial active emptying. Heart rate is the strongest determinant of atrial filling fraction and atrial velocities, as shown by Doppler echocardiography in children. ${ }^{22}$ There is also a steady state level in early peak filling velocity in children, suggesting that the diastolic properties of the left ventricle do not change greatly during childhood.

The present study is the first to report left ventricular volumes and function assessed by 3DE in relation to growth. Previous studies with MRI and 3DE have shown that 3DE is an accurate method for studying left ventricular volumes in children..$^{8-15}$ Left ventricular time-volume curves have been generated by MRI, ${ }^{5}$ radionuclide angiography, ${ }^{4}$ and recently by real time $3 \mathrm{DE} .^{23}$ Accurate determination of PER and PFR requires a temporal resolution of less than $40 \mathrm{~ms} / \mathrm{frame} .{ }^{24} \mathrm{In}$ this study, temporal resolution was on average 14 ms (mean 55 frames/heart cycle, range 25-85), showing different phases of heart cycle in most of the individual time-volume curves. The mean time-volume curves were calculated to obtain a visually informative way of presenting time-volume data on a large number of subjects. The calculation method used decreased the temporal resolution of the mean time-volume curves as compared with individual curves. Indices for left ventricular ejection and filling were calculated from individual 3DE data in children and adolescents of varying size. Our results were in accordance with earlier studies showing heart rate dependency of PER and PFR. ${ }^{45}$ Time-volume methods as well as Doppler echocardiography are strongly affected by heart rate, which may change rapidly during the study. It 
remains to be seen whether assessment of diastolic left ventricular function by $3 \mathrm{DE}$ will prove to have any advantages over the previously used methods in pathological conditions.

\section{Limitations of the study}

The major limiting factor of $3 \mathrm{DE}$ in clinical practice is the time needed for manual tracing of images. In our study, determining the volume of either the left atrium or the left ventricle during the heart cycle took an average of 45 minutes per patient. However, maximum and minimum volumes could be determined in five minutes, and these measurements could be adapted for clinical use even now. Further improvements in technology will provide us with accurate automatic border detection and will shorten the time needed for volume calculations. So far, the use of endocardial border detection has been reported to underestimate left ventricular volumes, while only a moderate decrease in the time needed for analysis was achieved. ${ }^{26}$

Respiratory gating was ignored in this study in order to shorten the image acquisition time and to allow the examination of small children without sedation. The harmful effect of filled lungs was avoided by using a left semirecumbent position and by finding optimal acoustic windows into the left atrium (parasternal window) and the left ventricle (apical window). The quality of 3DE datasets collected was suitable for analysis even in young adults. Data acquisition during several heart cycles may have led to a loss of data in late diastole because of physiological changes in heart rate. Image acquisition during several heart cycles produced an estimate of averaged volumes during both heart and respiratory cycles.

Ten image planes were chosen in order to obtain an image acquisition time short enough to allow small children to be studied. The number of image planes was predestined and was the same in all the children. There are 3DE studies that have reported acceptable accuracy for left ventricular volumes with precordial acquisition at $12-16^{\circ}$ intervals. ${ }^{27}$ Studies with the rapid apical rotational image acquisition technique have shown accurate quantification of left ventricular volumes with as few as four to six coaxial slices. Our 3DE method was also validated with MRI in 30 children, who are included in this study.

Real time echocardiography is expected to overcome problems related to the technology used in the present study. A matrix probe enables acquisition of instantaneous volumetric images without respiratory or ECG gating. ${ }^{28}$ Rapid image acquisition also decreases the risk of motion artefact.

The onset of atrial systole was considered to begin with the onset of the P wave on ECG. Although atrial systole starts after the $\mathrm{P}$ wave because of the electromechanical delay, this delay is short and left atrial volumes are not expected to change significantly from the onset of the $\mathrm{P}$ wave to the beginning of left atrial systole. ${ }^{29}$

The atrial appendage is a true part of the left atrium. However, its location may vary and the volume of the hooked and tube shaped appendage is not always easy to measure. Studies based on cross sectional echocardiography ${ }^{2320}$ or acoustic quantification of cross sectional echocardiography ${ }^{19}$ do not discuss the role of the atrial appendage. In an MRI study in adults the appendage was included in left atrial volume ${ }^{17}$ and in a $3 \mathrm{DE}$ study the appendage was excluded. ${ }^{7}$ As a reliable assessment of the left atrial appendage was not always possible in the present study its volume was excluded from the reported left atrial volumes.

Despite these limitations, the results presented provide a framework for further use of 3DE in children with various heart diseases. On-line 3DE volume measurements will soon be available in modern echocardiographic machines, which will undoubtedly increase the role of 3DE in clinical decision making.

\section{ACKNOWLEDGEMENTS}

This study was supported by the Foundation for Paediatric Research, Finland, and Parent Organisation for Children with Heart Disease, Finland

\section{Authors' affiliations}

T Poutanen, T Tikanoja, Department of Paediatrics, Kuopio University Hospital, Kuopio, Finland

E Jokinen, H Sairanen, Department of Paediatrics and Surgery,

University of Helsinki, Helsinki, Finland

\section{REFERENCES}

1 Gutgesell HP. Echocardiographic assessment of cardiac function in infants and children. J Am Coll Cardiol 1985;5:95-103s.

2 Pearlman JD, Triulzi M, King ME, et al. Left atrial dimensions in growth and development: normal limits for two-dimensional echocardiography. J Am Coll Cardiol 1990;16:1 168-74.

3 Hofstetter R, Bartz-Bazzanella P, Kentrup H, et al. Determination of left atrial area and volume by cross-sectional echocardiography in healthy infants and children. Am J Cardiol 1991;68:1073-8.

4 Magorien D, Shaffer P, Bush C. Assessment of left ventricular pressure-volume relations using gated radionuclide angiography, echocardiography and micromanometer pressure recordings: a new method for serial measurements of systolic and diastolic function in man. Circulation 1983:67:844-53.

5 Fujita N, Hartiala J, O'Sullivan M, et al. Assessment of left ventricular diastolic function in dilated cardiomyopathy with cine magnetic resonance imaging: effect of an angiotensin converting enzyme inhibitor, benazepril. Am Heart J 1993:125:171-8.

6 Roelandt JRTC Yao J, Kasprzak JD. Three-dimensional echocardiography. Curr Opin Cardiol 1998;13:386-96.

7 Keller AM, Gopal AS, King DL. Left and right atrial volume by freehand three-dimensional echocardiography: in vivo validation using magnetic resonance imaging. Eur J Echocardiogr 2000;1:55-65.

8 Papavassiliou DP, Parks WJ, Hopkins KL, et al. Three-dimensional echocardiographic measurement of right ventricular volume in children with congenital heart disease validated by magnetic resonance imaging. J Am Soc Echocardiogr 1998;11:770-7.

9 Altmann K, Shen Z, Boxt LM, et al. Comparison of three-dimensional echocardiographic assessment of volume, mass, and function in children with functionally single left ventricles with two-dimensional echocardiography and magnetic resonance imaging. Am J Cardiol 1997;80:1060-5.

10 Vogel $M$, Gutberlet $M$, Dittrich S, et al. Comparison of transthoracic three-dimensional echocardiography with magnetic resonance imaging in the assessment of right ventricular volume and mass. Heart 1997;78: 127-30.

11 Acar P, Maunoury C, Antonietti T, et al. Left ventricular ejection fraction in children measured by three-dimensional echocardiography using a new transthoracic integrated 3D-probe. A comparison with equilibrium radionuclide angiography. Eur Heart J 1998;19:1583-8.

12 Li J, Sanders SP. Three-dimensional echocardiography in congenital heart disease. Curr Opin Cardiol 1999;14:53-9.

13 Acar P, Marx GR, Saliba Z, et al. Three-dimensional echocardiographic measurement of left ventricular stroke volume in children: comparison with Doppler method. Pediatr Cardiol 2001;22:116-20.

14 Poutanen T, Ikonen A, Vainio P, et al. Left atrial volume assessed by transthoracic three dimensional echocardiography and magnetic resonance imaging: dynamic changes during the heart cycle in children. Heart 2000;83:537-42.

15 Poutanen T, Ikonen A, Vainio P, et al. Transthoracic three-dimensional echocardiography is as good as magnetic resonance imaging in measuring dynamic changes in left ventricular volume during the heart cycle in children. Eur J Echocardiogr 2001;2:31-9.

16 DuBois D, DuBois EF. A formula to estimate approximate surface area if height and weight be known. Arch Intern Med 1916;17:863-71.

17 Järvinen V, Kupari M, Hekali $P$, et al. Assessment of left atrial volumes and phasic function using cine magnetic resonance imaging in normal subjects. Am J Cardiol 1994;73:1135-8.

18 Arcilla RA, Thilenius OG, Chiemmongkoltip P, et al. Left atrial volume calculation by angiography in children. Chest 1973;63:189-97.

19 Spencer KT, Mor-Avi V, Gorcsan J, et al. Effects of aging on left atrial reservoir, conduit, and booster pump function: a multi-institution acoustic quantification study. Heart 2001;85:272-7.

20 Triposkiadis $\mathbf{F}$, Wooley C, Boudoulas $\mathrm{H}$. Left atrial volumes and function in normal subjects. Am J Noninvas Cardiol 1991:5:1-6.

21 Triposkiadis F, Tentolouris K, Androulakis A, et al. Left atrial mechanical function in the healthy elderly: new insights from a combined assessment of changes in atrial volume and transmitral flow velocity. J Am Soc Echocardiogr 1995;8:801-9.

22 Schmitz L, Koch $H$, Bein $G$, et al. Left ventricular diastolic function in infants, children, and adolescents. Reference values and analysis of morphologic and physiologic determinants of echocardiographic Doppler flow signals during growth and maturation. J Am Coll Cardiol 1998;32:1441-8.

23 Zeidan Z, Buck T, Barkhausen J, et al. Real-time three-dimensional echocardiography for improved evaluation of diastolic function using volume-time curves. Herz 2002;27:237-45. 
24 Bacharach SL, Green MV, Borer JS, et al. Left ventricular peak ejection rate, filling rate, and ejection fraction - frame rate requirements at rest and exercise: concise communication. J Nucl Med 1979;20:189-93.

25 Arsos G, Moralidis E, Karatzas N, et al. Heart rate is the major determinant of diastolic filling pattern during growth: a radionuclide ventriculography assessment. Pediatr Cardiol 2002;23:378-87.

26 Chuang ML, Beaudin RA, Riley MF, et al. Impact of on-line endocardial border detection on determination of left ventricular volume and ejection fraction by transthoracic 3-dimensional echocardiography. J Am Soc Echocardiogr 1999;12:551-8.
27 Nosir YF, Vletter WB, Kasprzak JD, et al. Optimal rotational interval for 3-dimensional echocardiography data acquisition for rapid and accurate measurement of left ventricular function. J Am Soc Echocardiogr 2000;13:715-22.

28 Lange A, Palka P, Burstow DJ, et al. Three-dimensional echocardiography: Historical development and current applications. J Am Soc Echocardiogr 2001; 14:403-12.

29 Toma Y, Matsuda Y, Moritani K, et al. Left atrial filling in normal human subjects: relation between left atrial contraction and left atrial early filling. Cardiovasc Res 1987;21:255-9.

\section{IMAGES IN CARDIOLOGY}

\section{Persistent truncus arteriosus with absence of right pulmonary artery}

T

he magnetic resonance angiography

(MRA) images of a 19 year old girl

with persistent truncus arteriosus are shown. Clinically, she has pulmonary vascular disease. Her chest $x$ ray (upper panel, middle column) failed to demonstrate a right pulmonary artery. MRA was performed to define the pulmonary anatomy better, as a noninvasive modality in this patient.

Orthogonal black blood studies of the heart and great vessels and 4CV FIESTA images were obtained, followed by gadolinium enhanced aortopulmonary arterial MRA.

The left pulmonary artery (lower panel, middle column) was seen to arise posterolaterally from the left side of the trunk, $3 \mathrm{~cm}$ above the truncal valve, dividing into upper and lower lobe branches as it entered the left lung. The absent right pulmonary artery was confirmed in the study.

However, there were two large aortopulmonary collateral vessels seen arising from the mid thoracic aorta, crossing in a tortuous turn to supply the right lung (upper and lower panels, right column). The upper vessel supplied the right upper lobe, while the lower vessel provided flow to the middle and lower lobes. The aortic arch was right sided.

The origin of pulmonary arteries in persistent truncus arteriosus is highly variable. Absence of either pulmonary artery branch in this condition has been reported only rarely. In those few cases, the pulmonary artery was absent on the side of the aortic arch, as in our patient.
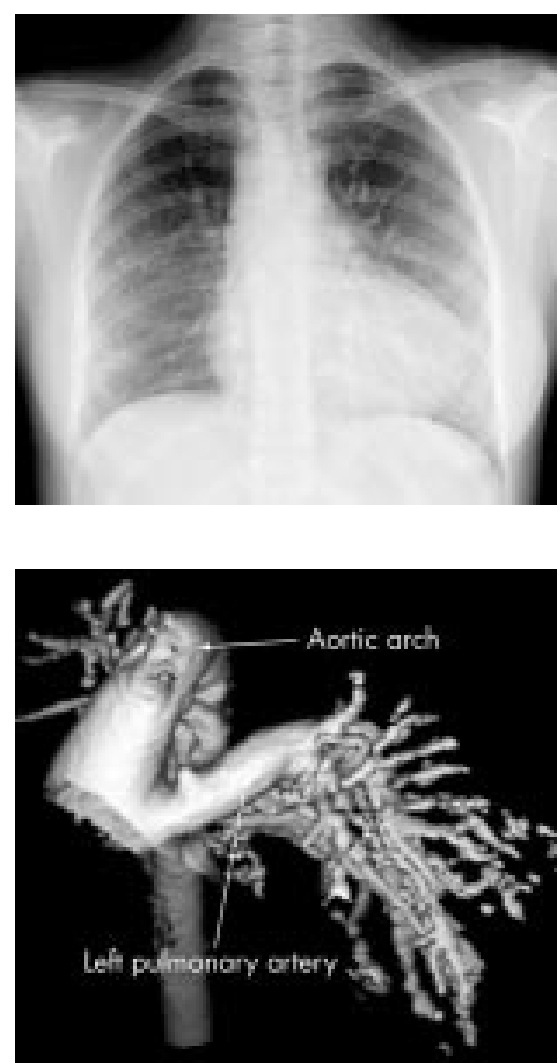

MRA is an excellent and non-invasive way of delineating the cardiac anatomy in structural heart disease.

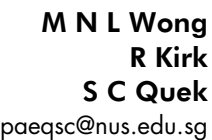

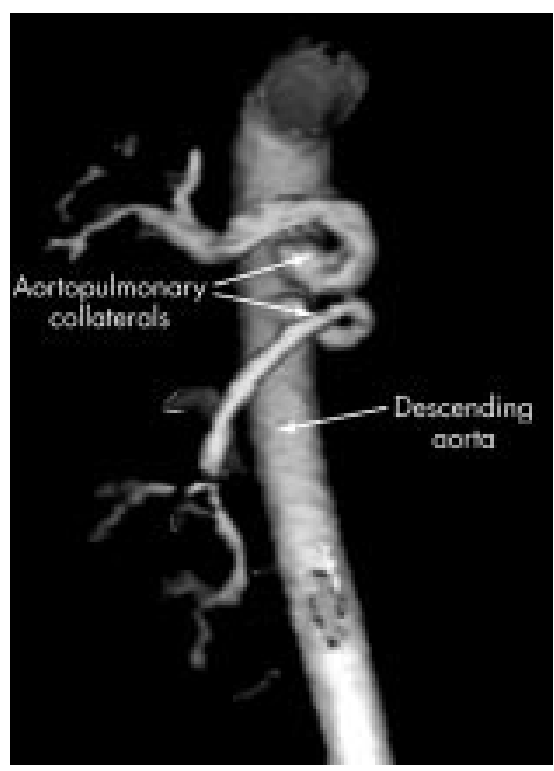

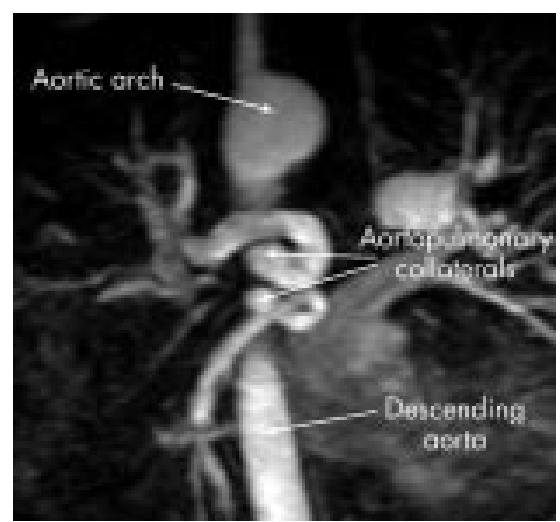

